УДК 101.1:316+613.43:004.925.84

\title{
ФЕНОМЕН СТРАХА И СМЕРТИ В ВИДЕОИГРАХ
}

\author{
Петев Николай Иванович, \\ cyanideemo@mail.ru \\ Владимирский государственный университет имени А.Г. и Н.Г. Столетовых, \\ Россия, 600000, г. Владимир, ул. Горького, 87.
}

Петев Николай Иванович, кандидат философских наук, доцент кафедры философии и религиоведения Владимирского государственного университета имени А.Г. и Н.Г. Столетовых.

Рассмотрены феномены страха и смерти в видеоиграх. Необходимо отметить, что в некоторых видеоиграх присутствует специфический нуминозный характер, который влияет на внутреннее содержание этих вышеуказанных явлений. В целом пространство и время виртуального мира игр, отличающиеся от субъективного мира, приводят к тому, что вне страха и смерти у индивида появляется особое состояние, страх и смерть обессиливаются, теряют свою энергию, категоричность. Актуальность исследования заключается в том, чтобы рассмотреть процесс борьбы со страхом и метаморфозы, которые происходят с ним, а также с индивидом в пространстве видеоигр. Цель работы: выявление специфики построения и презентации феномена страха и смерти в рамках пространства и сюжета видеоггр; определение особенностей внутреннего содержания данных феноменов, их герменевтический анализ для получения тех субстанциональных идей, которые отражают суть этих явлений; рассмотрение таких феноменов, как время, пространство, вживание и пр., в синтетическом переплетении, как искусственно создаваемую экзистенцию индивида особой формы. Методы исследования. Были использованы абстрактно-логический, сравнительный и герменевтический анализы для установления основных положений исследуемого вопроса. Кроме того, применены диалектический метод для более подробного анализа феномена страха и смерти, а также элементы религиоведческого анализа. Результаты. Через призму феноменов страха и смерти видеоигры осуществляют прорыв сознания индивида в некую сферу нуминозного (религиозного, сакрального, а точнее - в некую плоскость «совершенно иного» и отличного от профанной). Это необходимо в первую очередь для борьбы с обыденностью, которая ведёт к отчуждению индивида от самого себя. Иными словами, страх и смерть инициируют экзистенциальную чувствительность индивидуума. Видеоигры служат определённым механизмом (методом) борьбы с различными фобиями индивидуального, коллективного и архаического характера, придавая им конкретную (телесную, материальную, которую можно разрушить) форму. Видеоигры являются формой выражения танатологических (эсхатологических, иногда и апокалиптических) тенденций как некий компенсаторский компонент. Кроме того, стоит указать, что пространство, игровой процесс и искусственная реальность этих игр способствуют реализации телеологии, этиологии, героической этики, «бессмертия» индивида и выходу за рамки собственной экзистенции (в частности, в аспекте понятий времени и пространства), используя для этого страх и феномен смерти как инструмент.

Ключевые слова: Видеоигры, страх, смерть, нуминозное, «отчуждение от смерти», «божественность», время, пространство.

Первое, что необходимо отметить при исследовании феномена страха и смерти в видеоиграх - это момент нуминозного (сакрального, священного, религиозного), который присутствует в видеоиграх. Сразу необходимо отметить, что, говоря о видеоиграх, мы имеем в виду сложные и содержательные по своей сюжетной линии и игровому пространству игры (такие как серия Silent Hill, Dead Space, F.E.A.R, Resident Evil, Left 4 Dead, Warhammer 40.000, Amnesia: The Dark Descent и т. д. Или отдельные игры не- 
больших компаний, такие как Downfall: A Horror Adventure Game, The Cat Lady, Lorelai и т. д.) в стиле хоррор или обладающие его элементами в различной степени. Отто Р. указывал, что встреча с «numen» всегда имеет характер столкновения с чем-то совершенно иным, что будоражит наше сознание [1]. Иными словами, это встреча с тем, что не похоже на нас или нашу собственную экзистенцию с её формой, качеством и внутренним содержанием. Более того, «numen» не поддаётся рациональному осмыслению и формализации (1). Это момент новизны, чего-то совершенно иного, что ранее не имело места в сфере наших, чувств, опыта, мышления и т. д.

В целом к чему-то новому человек относится очень осторожно. Например, Ф. Ницше указывал, что для человека характерно не принимать всё новое, а причинность искать в чём-то совершенно знакомом, а точнее - в предпочитаемом [2]. При этом такое положение вещей приводит к полному устранению нового, в том числе и из аксиологической системы. Ведь равнодушие и неприязнь есть обедняющая и разлагающая предмет реакция [3]. Хотя стоит отметить, что игнорирование - это функция экономии, в частности биологическая, оберегающая от рассеивания [3]. Тем не менее абсолютное отрицание нового формирует косность индивида и общества, что приводит к потере индивидом экзистенциальной «эластичности», т. е. адекватной реакции на те изменения и тенденции объективного мира, что главенствуют и требуют от индивида определённой рефлексии.

Существует и иное мнение о том, как воспринимается «новое» индивидом. Б. Паскаль указывал на то, что новизна ослепляет и увлекает нас [4]. Т. Гоббс отмечал, что радость от нового возбуждает в человеке особый когнитивный восторг, толкающий человека на поиск причины [5]. Другими словами, нечто новое привлекает индивида, заставляя искать причину того, почему оно отличается от того, что было ранее. И в таком поиске причинности может возникнуть ошибка или же подмена её содержания. Если же причина того или иного феномена «нового» остаётся для человека непознанной или же не несёт никакого практического (утилитарного) характера или, например, ввиду радикального конформизма индивида, то новое отрицается (вплоть до дефиниции его как чего-то негативного и деструктивного). Специфика нуминозного заключается в том, что какими бы неоднозначными качествами оно не обладало, оно тем не менее увлекает человека, вводит его в некое дионисийское (экстатическое) состояние. Даже если нуминозное обладает некими антагонистичными индивиду качествами, он всё равно им увлекается. Это момент контраст-гармонии, т. е. чем страшнее (отвратительнее, грубее) это нечто, тем более оно привлекает, опьяняет и увлекает за собой. Это так называемое негативно-нуминозное - одна из сторон сакрального. Подобное влечение к «негативному» особенно характерно для современного человека. Чем более что-либо отклоняется от нормы (социальной, психологической, моральной и т. д.), тем оно ему более интересно. При этом реализация даже противоестественных и нелегитимных актов воспринимается сообществом как некая творческая самореализация и индивидуализм (2). Данная ситуация происходит вследствие излишней рационализации, искажающей многие естественные понятия, духовной секуляризации и косности религиозности как феномена общества. Стоит отметить, что для архаического сознания не была свойственна чёткая дифференциация добра и зла в религиозном аспекте, как, например, в религии индейцев Месоамерики [6], но такое положение как раз было вызвано феноменом нуминозного, а в парадигме экзистенции современного человека речь идёт больше о кризисе сакральности, чем о факте прорыва нуминозного.

Мир видеоигр кажется нам чужим, нереальным, странным, ибо он отличается от нашего объективного мира. Он релятивен, не реален, как говорит нам наш разум. Но он 
превосходит по всем своим параметрам нашу экзистенцию, и это находит отражение в нашем иррациональном в форме нуминозного. Р. Отто описывал это как некий опьяняющий и упоительный эффект момента «fascinans» [1], который имеет место при встрече с чем-то новым, иным. Конечно, нельзя сравнивать ту глубину проникновения нуминозным архаического человека и игрока. Возможно, причина того, что нуминозное проявляется не так ярко и глубоко у современного человека по сравнению с архаичным кроется в высоком уровне рациональности, развитом интеллекте и том факте, что априори человек осознаёт, что это игра, т. е. продукт его деятельности. Но именно мир видеоигры вызывает прорыв религиозного (нуминозного), т. к. традиционные формы и методы уже не эффективны, а видеоигра по своей архитектонике и внутреннему содержанию способна удовлетворить потребность индивида в иррациональном (3).

Видеоигры, подобно религии, ведут некую специфическую борьбу с самыми сильными и страшными врагами человека - это страх (4) и смерть. Они являются достаточно яркими феноменами, сущность и специфика которых раскрывается как в научной, так и в художественной литературе, а также в кинематографе, искусстве, религии и т. д. Страх и смерть рассматриваются с различных сторон и, как правило, указывают на видение того или иного интерпретатора. Несомненно, что феномены страха и смерти имеют богатое внутреннее содержание и им сложно дать чёткую дефиницию. Э. Фромм отмечал, что человек постоянно находится в состоянии обыденности и рутины, что ведёт к его отчуждению от самого себя (своих качеств, личности, особенностей ментальности - что, по сути, не является необходимым для этой самой рутины) [7]. Интересно высказывание Э. Фромма о том, что религия и искусство, которые должны были выводить человека из такого состояния, уже не выполняют данной функции [7]. Они сами стали новой формой обыденности, против которой сами же и боролись. Искусство - это мирская форма борьбы с повседневностью, вступающая в противостояние с теоретическим и практическим рационализмом [8]. Последним обладает современная форма религиозности, в которой присутствует некая экзистенциальная косность, отражающаяся в излишней теоретичности и формализме. М.М. Бахтин отмечал, что как для теоретического мира, так и чисто эстетического недоступна причастность к объективному бытию [3]. И действительно, не это ли необходимо человеку для ухода от обыденности. К сожалению, чрезмерная оторванность от реального мира, если она не сопровождается прорывом нуминозного (в котором индивид чувствует своё присутствие), воспринимается нашим разумом лишь как фикция и релятивность. Благодаря деформированным формам религии, искусству и излишней рациональности, многие феномены, в том числе в чувственной области, потеряли свои качества и не спасают от обыденности. Однако смерть и страх - это те элементы человеческого бытия, которые остались нетронутыми, и они до сих пор пробуждают в человеке чувства тварности, существования, жизни. В отличие от архаического человека, который постоянно находился в состоянии страха [9], современный индивид находится в относительном комфорте и безопасности, в частности от многих явлений природы и яростных стихий, ввиду чего его сопричастность к жизни имеет атрофированный характер.

Э. Фромм указывал, что драматизм - это та необходимость человеческого бытия, которую ищет человек для выхода из состояния обыденности [7] и, как следствие, ступень к самоотождествлению. А. Бергсон также отмечал, что драма даёт новую жизнь чувствам, желаниям и привязанностям [10]. Человек создал внешний (общий для всех) покров чувств и эмоций, дабы затушить или прикрыть жар индивидуальных страстей, но драма позволяет этим чувствам и эмоциям выйти наружу [10]. В противовес форма- 
лизованной системе установленной «чувственности» драма раскрывает нечто личное, индивидуальное, интимное, что скрыто внутри человека. Она указывает на травматический компонент нашей экзистенции, затрагивая самые потаённые уголки человеческих чувств, эмоций и переживаний, в том числе такие, как страх и смерть, которые вуалируются повседневностью и индивидуальной отчуждённостью.

Поскольку традиционные формы такого «выхода» претерпевают кризис, человек ищет методы и сферы, чтобы компенсировать необходимое иррациональное. К таким сферам и методам можно отнести и видеоигры, которые имплицитно, а иногда и эксплицитно в форме религиозных (или околорелигиозных) мотивов, включают в себя элементы нуминозного. Страх и смерть в них будоражат сознание индивида, позволяя ему выйти за рамки обыденности, в которых он постоянно находится в своей экзистенции. Таким образом, удовлетворяется необходимость самоотождествления, т. к. обыденность инициирует оторванность индивида от себя и окружающего мира.

Видеоигры - это та плоскость, та сфера, в которой индивид вступает в схватку со страхом и самой смертью (5). Одним из ярких примеров борьбы со страхом смерти является поведенческая парадигма самураев средневековой Японии. Дело в том, что самураям присуща медитативная ежедневная практика, во время которой индивид не только представляет свою смерть, но и различные её формы [11]. В первую очередь это было направлено на то, чтобы избавиться от страха перед смертью. В результате происходил перенос этих феноменов из ряда вещей будоражащих, необычных и даже сакральных в ряд вещей обыденной экзистенции, таким образом, обезоруживая их в аспекте своего влияния на индивида (его образ мышления, поведение, поступки, мысли и т. д.).

Почему же возникает страх в человеке? Мнений по данному вопросу существует множество. Однако большинство склоняется к гносеологическому аспекту, а именно к незнанию причины того или иного феномена. Например, С. Кьеркегор отмечал, что источником страха является заблуждение [12], в том числе и в вопросе о причинах (6). Ф. Ницше писал, что «стремление находить причины обусловливается и возбуждается чувством страха» [2, с. 50]. Т. Гоббс указывал, что страх без причины вызывает панический ужас, а люди следуют за тем, кто, по их мнению, знает причину [5]. Эпикур утверждал, что как только мы поймём причину - страх исчезнет [13].

Особенный страх вселяет то, что не имеет конкретной формы, является чем-то аморфным, что не поддаётся дефиниции или категориальному анализу. Аморфность мыслится чем-то абсолютно единым и не имеющим конечности, а соответственно неуничтожимым и неразложимым. Всё это противоречит принципу конечности человеческой экзистенции и объективного мира (даже в рамках постоянного уничтожения и создания (воссоздания)). Если подобные образы переносятся на что-то конкретное (явление, персонаж и т. д.), то, несомненно, что оно будет вызывать определенное отношение, в частности страх, если его существование исключает существование воспринимающего.

Несмотря на то, что страх - это лишь внутреннее напряжённое состояние индивида, которое инициировано какими-либо внешними условиями, в видеоиграх он обретает конкретные формы (7). Человек всегда ищет различные методы и способы борьбы как с собственными страхами, так и со страхами архаического (архетипического) характера. Монстры, чудовища, демоны и мертвецы - это одновременно репрезентация как индивидуальных (коллективных (8)) страхов, так и архаических, имеющих исток в религиозно-мифологическом сознании индивида [14]. Все эти страхи и ужасы не только обретают в видеоигре причину (9), которая, как правило, обусловлена самим героем 
(игроком), ибо без него нет сюжета истории, но и наделяются формой и материей (10). Таким образом, любой страх становится вещью как бы мира объективной реальности (имеет цель, причину, материю и форму), а соответственно конечным и уничтожимым.

С. Кьеркегор отмечал, человеческая жизнь в отчаянии (которое может быть, по сути, инициировано или сопряжено с идеями страха и смерти) - это состояние постоянного умирания, процесс умирания, умирать смертью (иными словами, переживать свою смерть вечно) [12]. Не стоит перечислять как много вещей и явлений нашего мира, в частности в сфере обыденности, могут инициировать это состояние отчаяния. Достаточно пессимистично, но фактически - близко к правде. Но мы, если исключить фактор отчаяния, не замечаем наличие смерти ежеминутно. Ещё М. Хайдеггер отмечал, что в повседневной жизни человек не имеет никакого соприкосновения со смертью, даже если кто-то умирает, мы не чувствуем её, для нас её как бы нет [15]. Мы обретаем некое состояние «бессмертия». Но выше мы говорили, что обыденность ведёт к распаду личности индивида. А видеоигры одновременно сохраняют подобное состояние «бессмертия» и не вызывают отчуждения от себя, т. к. именно через них индивид проявляет себя, ему нет необходимости отсекать от себя те компоненты, которые не имеют значения в объективном мире или нет возможности их проявить. Это и есть момент «отчуждения от смерти». Она становится не такой неизбежной, роковой и неумолимой. Смерть уже не вызывает страха. Смерть не кажется абсолютной, всеобъемлющей и категоричной. Она теряет свой статус онтологического нерушимого закона. Она становится не только чем-то тривиальным, но даже тем, чего можно избежать. Происходит её экзистенциальное обесценивание, что, в свою очередь, ведёт к обесцениванию жизни (11). Ведь только в их соотношении можно понять ценность обеих (12). Видеоигры являются специфической формой выражения танатологических (эсхатологических, иногда и апокалиптических) тенденций как некий компенсаторский компонент (функция): иными словами, эта некая экзистенциальная, в том числе психологическая, разрядка напряжения индивида, для которой характерно снижение степени влияния мотивов смерти и страхов.

В видеоиграх существует особый момент «вечного возвращения». Человеческая экзистенция предполагает альтернативу в возможности, но в действительности акт исполнения будет иметь единичный и единственный характер, т. е. один из нескольких потенциальных. И это возлагает на человека определённую ответственность, ведь через подобный акт-поступок формируется единственность бытия [3]. Другими словами, оно наполняется содержанием, которое мы привносим через решение. Однако видеоигра снимает эту ответственность, т. к. игрок всегда может вернуться в момент принятия решения и сделать иной выбор, т. е. существует возможность реализации вариативности из одной онтологической точки (13). Это устраняет страх неизвестности и решает проблему смерти как некого будущего, неожиданного феномена.

В объективном мире настоящее практически не зацепляемо нашим разумом, оно моментально становится прошлым или находится в состоянии энтелехии будущего. Видеоигра позволяет нам приобщиться к настоящему через возвращение к определённой точке, при этом в полном объёме имея представление о будущих событиях. Происходит момент бессмертия и устранения страха, т. к. любое будущее событие уже известно и можно выбрать наилучшую парадигму действий.

Видеоигры дают возможность индивидууму реализовать принцип «героической этики». Она присутствует в культурах многих народов. Наиболее ярко проявилась у скандинавских племен (викингов). Эта форма этики предполагает победу индивида над страхом, в том числе страхом смерти, и инициирована тем, что в системе ценностей, 
слава и героизм стоят выше, чем жизнь. Дело в том, что смерть для викингов - это тот момент славы, когда воин обретает свою абсолютную завершённость, реализацию [16]. Слава - это главная ценность героической этики. Более того, просто умереть - это ещё не путь к бессмертию. Умереть нужно красиво, так, чтобы потомки помнили и восхищались, - только в этом бессмертие [17]. Поэтому приемлемой являлась лишь смерть в битве. Это подобно пониманию смерти самураями. Для самурайской традиции Японии была характерна особая эстетизация смерти, которая называлась «искусство умирать». Главный принцип был таков: жизнь человека считалась тем прекраснее, чем она короче, особенно если это «ярко» прожитая жизнь [18]. Отсюда и проистекала небоязнь смерти. В современном мире те или иные условия, как личностные, так и экзистенциальные (экономические, политические и т. д.), не позволяют индивиду реализовать необходимость и стремление к данной форме этики. Однако именно видеоигры дают возможность это желание реализовать. Это ещё один момент борьбы со страхом и смертью.

Также видеоигры затрагивают один из центральных вопросов человека - это телеология и этиология существования. Это общефилософские вопросы, на которые нет однозначных ответов. Их слишком много, поэтому человек может затеряться в их многообразии. Кроме того, для индивида нет ничего ужаснее бесцельной экзистенции и незнания причин, ведь именно это вызывает жуткий страх. Религия старается ответить на эти вопросы, несомненно, в рамках идеализма. Наш разум не способен дать нам однозначный ответ, который хотя бы один раз не подвергался сомнению. Даже если мы решим, что наша причина и цель в этом, то неизвестно, позволит ли нам объективный мир реализовать то, к чему мы предназначены. Религия же, как правило, указывает на метафизический характер цели и причины, позволяющие упускать факторы материального мира, что создаёт эффект истинности данной нам телеологии и этиологии. Видеоигры отличаются тем, что цель и причина (сюжет в целом, персонаж и т. д.) обоснованы и их реализация является сутью самой же игры. Подобно тому, как в религии человеческая экзистенция есть реализация какого-то конкретного замысла (причины), так и в игре - так или иначе, у персонажа есть четкая цель и обоснованная причина его наличия. Важно отметить ещё один момент - многим индивидам недостаточно иметь простого обоснования своего существования как обычного биологического процесса, в том числе с целью продолжения рода. Фромм Э. указывал, что «жизнь не может быть «прожита» путем постоянного повторения модели своего вида» [19, с. 91]. Человеку необходим иной, более глубокий и высокий смысл. Такой смысл часто даёт религия. И такое же особое предназначение существует у протагонистов игр.

Что касается этиологии, то в играх данный феномен имеет ещё одну важную специфику. М. Элиаде отмечал, что знать миф, значит приблизиться к тайне происхождения вещи [20], а обладание знаниями о её происхождении равносильно приобретению господства над ней [20]. Такое же мнение высказывал Л. Леви-Брюль, что понимание вещи или явления даёт большую власть над ними [9]. Таким образом, зная миф о смерти, мы имеем определённую власть над ней: возможность отсрочить её, избежать, перехитрить и т. д. Отсюда возникает большое число мифов, повествующих о том, как герои (иногда боги) искали способы обретения бессмертия. Иными словами, имея знания о причинах смерти, существует возможность как бы «завладеть» ей. Видеоигра репрезентует подобное «владение», которое ярко отражено в мифологемах различных религий. Таким образом, смерть теряет некую свою мистику, таинственность, неизвестность, что обезоруживает её, ведь сама игра и есть причина смерти и ей определена 
(ограничена, поставлена в рамки, имеет пределы). Такая же тенденция наблюдается и в аспекте страха (14).

Ещё один ключевой момент, связанный с феноменами страха и смерти, который существует в видеоиграх, - это вопрос времени и пространства. Б. Паскаль отмечал, что наше настоящее всегда нам в тягость, мы живём или прошлым или будущим [4]. В свою очередь, Б. Спиноза указывал, что страх в нас возникает при идее вещи прошлой или будущей, о которой нам точно ничего не известно [21]. Таким образом, время для человека носит неоднозначный характер, особенно если учесть то, что он конечен, т. е. смертен. Время часто вызывает страх, как некие события будущего или прошлого. Пространство видеоигр предполагает своё особое время, отличное от времени объективного мира. Всё оно сливается в единый поток настоящего, здесь и сейчас, ведь прошлое известно, а будущее будет известно при возвращении в какой-то момент прошлого (например, через загрузку сохраненного этапа игры или контрольной точки). Пространство видеоигр имеет другие характеристики, отличные от человеческого мира, что даёт человеку больше возможностей (как индивидуальных, так и экзистенциальных). Кроме того, динамика игры увлекает индивида из сферы объективного времени и пространства, вводя его в совершенно иное. Подобная специфика присуща, например мифологии. Ведь время мифов - это совершенно иное время, не измеримое человеческими мерками. Дж.Ф. Бирлайн указывал, что «Священное время - это совершенно отдельное время для отдельной реальности, лежащее за пределами часов и календаря и отмечающее наши встречи с Вечным» [22, с. 25]. В этом можно заметить ещё один момент взаимоотношения религиозного (нуминозного) и видеоигр: подобно мифу, время и пространство игры уничтожает абсолютизм и категоричность страха и смерти.

Но если пространство видеоигры так отличительно от нашей экзистенции, то почему оно не внушает нам дикий и необузданный страх, ведь например, для архаического человека любая аномалия внушает страх (15) [9]. Конечно, наше сознание и мышление, с одной стороны, стоят на ступень выше, ибо причинно-следственная связь и глубокое погружение в предмет через его анализ позволяют найти естественные причины тех или иных феноменов, с другой - если причина не найдена, то индивид может сделать окончательные выводы, в том числе и о причинности, исходя из своего воображения. Такое положение вещей может привести к радикальным иррациональным идеям, которые могут инициировать дикий, первобытный и необузданный страх. Р. Барт указывал, что если пространство под влиянием того или иного феномена явлено в некой мягкой, мирной и неподвижной форме, т. е. в состоянии завершённости, то это устраняет смятение и страх [23]. Такова субстанциональная основа пространства видеоигр. Несмотря на то, что этот мир имеет сакральный характер, «иной» и пугающий, на первый взгляд, тем не менее из него устранёна та опасность, которая вводила бы человека в состояние дикого ужаса, без осуществления перехода к нуминозному.

Если пространство и время видеоигр обладают такими специфическими характеристиками, как описано выше, то можно ли говорить об их автономности по отношению к объективной реальности индивида. Если утверждать абсолютную автономию мира видеоигр, то из этого следует, что к нему не причастны ни разработчики игр, ни соответственно играющий. В таком случае в анализе онтологии видеоигр не имеет смысла исходить из понятий времени и пространства человеческой экзистенции, ведь автономность мира видеоигр абсолютизируется. Тогда положение вещей таково, что мир видеоигры - это специфическое метафизическое пространство или область ортофизичеких понятий и положений (которая стремится к метафизике нового уровня). В первом случае получается, что мир видеоигр сказывается только о себе, не имеет мо- 
мента творения и вечно существовал до физического пространства объективной реальности, т. е. до человека (16). А это нарушает причинно-следственную связь генезиса игр, исключая человека из процесса их создания (даже учитывая момент того, что именно через него этот мир приобретает воплощение). Что касается области ортофизики, то она не исключает объективный (физический) мир. Несомненно, что пространство и время видеоигр существует в состояние «ехо» (вне) или «parapano» (выше), однако такое положение только усложняет анализ феномена видеоигры и вызывает больше противоречий и вопросов, чем решений и ответов.

Стоит также отметить, что если мы признаем абсолютную автономность мира видеоигры, то очевидно, что по своему характеру он будет чем-то трансцендентным, некой «вещью в себе». Если виртуальный мир игры никаким образом не исходит из объективного мира (через человека), следовательно, мы никогда не сможем познать его, проникнуть в его суть (17). Достаточно сложно представить исследование, полностью исключающее исследующего (мыслящего), который является частью объективного мира (18). В таком случае стоит предположить, что трансцендентальный опыт мог бы стать ключом к пониманию внутреннего содержания видеоигр, однако тогда пришлось бы исключить категоричную автономность игрового пространства (19). Несомненно, эмпирический компонент, который связан с физическим (объективным) миром, имеет особое значение при исследовании видеоигр. Можно подойти к вопросу автономности мира видеоигр с точки зрения интуитивизма (возможно с элементами мистицизма), однако суждения и положения будут шаткими и спорными, что вызовет полемическую реакцию. Так или иначе, в контексте метафизической реальности проблема смерти и страха не имела бы места по причине того, что и этих феноменов не существовало бы, т. к. они скорее свойственны объективному миру с его качественными характеристиками, которые тем не менее имеют место в видеоиграх.

Существует проблема соотношения игрока и разработчика в пространстве видеоигр, в частности в аспекте активного и пассивного присутствия в виртуальном мире. Действительно, разработчик присутствует только при создании игры. Он своеобразный Демиург, но не платоновский «ремесленник». Если демиург Платона берёт материю и идею извне, создавая вещь, т. е. творение не исходит из него, то разработчик черпает идеи пространства видеоигры из самого себя, ведь это своеобразный акт творчества личностный и индивидуальный, исходя из такого материала (платформы, ресурсов), которые имеются. В данном контексте разработчика можно рассматривать в рамках деистической парадигмы. Несмотря на то, что игрок непосредственно не участвует в творении пространства (в создании самой игры), однако впоследствии, играя в неё, он влияет и изменяет созданное разработчиком пространство. В данном аспекте игрок аналогичен героям мифологических традиций (20). Он заполняет пространство виртуального мира, меняет его через свои действия (21) (действия своего персонажа). Игрок и разработчик - творцы пространства видеоигры. Разработчик присутствует имманентно, опосредовано, т. к. он изначально реализовал свою идею в игре; игрок - непосредственно, т. к. он актор (22) в этом пространстве.

Видеоигры позволяют осуществить стремление человека выйти за рамки своей экзистенции. Другими словами, прожить иные жизни, с иными событиями, в иное время. Здесь присутствуют компенсаторские функции видеоигры - отсутствие экзистенциальных ограничений, присущих человеческому существованию, позволяют реализовать желания и потребности, которые не могут быть осуществлены в объективном мире (23). Также в данном случае можно говорить об аспекте некого состояния «бессмер- 
тия», т. к. индивид проживает множество жизней героев игр, однако сам он подобен богам - бессмертен и не ограничен жизнью смертного (жизнью персонажа).

В игре присутствуют мотивы креационизма и провиденционализма. Зачастую это свойственно тем играм, где человек играет не за конкретного персонажа, а за определённый народ, расу или цивилизации. Он определяет их качественные характеристики, процесс развития, эволюцию и т. д. Это инициирует в индивиде своеобразное состояние отчуждения от смерти и страха - состояние «божественности», которому не свойственны категории человеческой экзистенции. Это состояние вне пространства и времени этого народа (расы, цивилизации), которое становится некой мистификацией, подменой, при которой управляемый виртуальным мир становится как бы объективной реальностью, а игрок по своим качествам (атрибутам) находится вне его закона.

Приобщение к событиям и некое особое вживание индивида в мир видеоигры указывают на определённую связь с мифологическим сознанием (воспроизведение мифа, инициация и т. д.). Видеоигры есть специфическая форма изложения, в частности каких-либо событий. Многие религиозные ритуалы религий мира носят такой же характер - восстановление сакральных событий. Иными словами, человек не только одновременно воспроизводит их, т. е. копирует, приобщается (становится их частью), но и реализует эти события здесь и сейчас как первоисточник. Подобное отмечал М. Элиаде, рассматривая инициацию как воспроизводство космогонического мифа [24]. Специфика космогонического мифа заключается в его особенном статусе вне категорий человеческого бытия, в том числе понятий страха и смерти. Это же можно отметить и в видеоиграх.

Но возникает вопрос: ведь существует опасность того, что человек может вжиться в роль настолько, что потеряет сам себя, т. е. утратит связь с реальным миром, ведь зачастую страх и смерть становятся теми факторами, что «отрезвляют» человека, выводят его из состояния обыденности. Действительно, такая опасность существует, однако она не является массовой. Вживание, конечно, отчуждает человека от объективного мира, но только в той степени, как это должны делать религия и искусство, т. е. для компенсации иррационального и выведения человека из сферы обыденности. М.М. Бахтин отмечал, что акт вживания никаким образом не нарушает структурную целостность личности и что полного вживания не может быть, т. к. постоянно в индивиде присутствует момент объективизации [3]. Действительно, некое особое вживание, которое сопровождается особой чувствительностью, инстинктом понимания и разгадывания, чуткой реакцией и достаточно интенсивной рефлексией (откликом) свойственно дионисийскому состоянию [2]. Такое состояние характеризуется высокой степенью восприимчивости и внушаемости. Поэтому если бы религиозное всегда брало верх над личностью, то каждый, кто проходил инициацию, становился бы шаманом, т. к. этот момент погружения в сакральное брало бы верх над индивидуальным. Подобное присутствует и в сфере видеоигр. Кроме того, в современном мире для «шаманов видеоигр» есть все условия, дабы не отчуждаться от реальности (они делают это своей профессией). Таким образом, некий элемент дионисийского состояния, инициированный видеоигрой, существует в архитектонике личности, однако своего личностного, волевого намного больше (24).

Особый вопрос видеоигр - это этический вопрос. Многие критикуют видеоигры за то, что в них присутствует множество деструктивных элементов (убийства, насилие, страх, безумие, психологические расстройства и т. д.) (25). Несомненно, что такое замечание является обоснованным. Однако если мы рассмотрим видеоигры в парадигме нумизнозного (сакрального), то становится понятно, почему эти элементы присутству- 
ют. Нуминозное не является тождественным нравственному, особенно в христианском понимании морали, хотя, как отмечал Р. Отто, сакральное всегда религиозно (то, что превосходит нас, возводится в степень религиозного, в частности веры) [1]. Для архаического человека нравственность являлась не строгой системой, а скорее следствием постоянной трансмиссии традиций (конечно, не без нравственных элементов) и некого естественного нравственного закона (26). Поэтому страх и смерть в данном контексте направлены на то, чтобы вывести человека из рамок обыденности (отчуждённости), затронуть самые архаические элементы его личности (подсознания), воззвать к его «жизненности».

\section{ПРИМЕЧАНИЯ}

1. Р. Отто указывал, что опыт нуминозного индивидуален, не рационален, и не может быть объяснён рациональностью [1]. Подобное мы можем заметить в переживаниях игрока в видеоиграх. Во-первых, даже относительно детерминированная сюжетная линия вызывает у разных индивидов разное отношение. Во-вторых, в соответствии с сюжетом игры персонаж (и соответственно игрок) принимает иррациональные решения, в частности иногда противоречащие закону самосохранения. Б. Спиноза отмечал, что «каждая вещь, насколько от нее зависит, стремится сохранить свое существование» [21, с. 130]. Но в играх наблюдается тенденция на определённое самоотречение и самопожертвование протагониста ради какойлибо цели в противовес естественному чувству самосохранения.

2. Дело в том, что в современном мире индивидуальность принимает деформированные формы, которые никоим образом не указывают на её наличие. Ф. Ницше отмечал, что «стать «индивидуальным» - в этом добродетель безличных» [2, с. 91]. Э. Фромм указывал, что попытка западной культуры воспитать человека с индивидуальным мышлением привела к тому, что лишь единицы добились этого, для остальных индивидуальность - лишь внешний фасад [19, с. 95]. Подобная ситуация наблюдается и в современном обществе. Часто недостаток личностности драпируется ярким мертвым эстетизмом, дабы скрыть её отсутствие.

3. В частности, для такого особого экзистенциального состояния характерны страх и идея смерти, как в имплицитной, так и эксплицитной форме. Они способствуют возбуждению особой экзистенциальной «чувствительности» индивида к реальности, объективному миру, к своему собственному внутреннему устройству и содержанию.

4. Отметим, что существуют концепции и исследования, согласно которым видеоигры - это сложная форма культуры, которая направлена на формирование определённого состояния индивида, характеризующееся контролем над страхом [25].

5. Стоит указать, что видеоигры способны вызывать в играющем особое чувство сопричастности феномену смерти, размышлению о ней и собственной смертности, что вызывает как положительные, так и отрицательные эмоции, а также представляют собой попытку побороть страх смерти [26].

6. Дж. Ролз утверждал, что человек судит (выбирает) не по тому, как много он знает, а как логически рассуждает при наличии имеющейся информации [27].

7. Субъективно страхи могут существовать вечно, иметь безграничное влияние, непреодолимую силу и энергию, но объективно - их положение в действительности очень шатко, любое событие способно их развеять, обессилить, лишить власти.

8. Например, Рэйчал Дюмас (Raechel Dumas) в своей книге The Monstrous-Feminine in Contemporary Japanese Popular Culture (East Asian Popular Culture) (Чудовищно- 
Женское в современной японской популярной культуре (восточноазиатская популярная культура)) указывает, что такие образы сформированы в рамках амбивалентных чувств (удовольствия и неудовольствия) в рамках социальнополитической обстановки Японии [28]. Более того, в одной из глав (Corrupted Innocence, Sacred Violence, and Gynoid Becomings: The Monstrous-Feminine on the Gaming Scene (Разложение невиновности, Священное насилие и становление гиноида: чудовищный-женское на игровой сцене)) она рассматривает половое различие как средство для разработки страхов, а игры - как средства преодоления противоположности телесности и технологий [28, с. 131-169]. Однако стоит отметить, что данный процесс приводит к подрыву традиционных форм идентичности, а также к разложению консервативных положений, в том числе в рамках нравственной парадигмы.

9. Причина - это то содержание вещи, из чего она возникает; форма или первообраз; определение сути бытия [29]. Причина событий игры - сама игра, её сюжет предопределён, все события, персонажи и пр. являются прямым следствием архитектоники игры, в ином случае конкретная игра уже не было бы этой игрой. Стоит указать на то, что игроку априори известна причина (в разной степени иногда она открывается по ходу сюжета, но тем не менее она лишь дополняется новыми элементами). Таким образом, в данном контексте можно говорить о том, что такие феномены, как страх и смерть, обессиливаются в рамках этиологической концепции.

10. Стоит отметить, что интересна мистификация в игре, связанная с вопросом материи и формы существ, антагонистических главному протагонисту. Дело в том, что, как правило, противник в игре предстаёт как некая неумолимая сила, как бесконечный поток, огромная масса, имя которому «легион». Первоначально данное положение указывает на некую беспредельную и неистощаемую силу, которая противостоит герою. Тем не менее такой легион не обладает такими характеристиками, как количество (множество, которое не является не непрерывным в своих частях [29]) и предел. Предел же - это то, за границей чего не представляется наличие чего-либо или его частей, и внутри чего оно находится [29]. Действительно, огромное количество монстров и чудовищ не столько указывает на тот факт, что это некая непреодолимая сила, сколько на то, что они лишь составные части чего-то иного, а следовательно - имеют предел, конечны и необходимы. Они обретают форму чего-то обыденного, проходящего и преодолимого.

11. М.М. Бахтин указывал, что «равнодушная или неприязненная реакция есть всегда обедняющая и разлагающая предмет реакция: пройти мимо предмета во всем его многообразии, игнорировать или преодолеть его» [3, с. 59]. Из подобного положения следует, что, с одной стороны, видеоигры обедняют внутреннее содержание понятия смерти и одновременно влияют на понятие жизни (её качественные характеристики, отношение к ней и т. д.), с другой стороны - это тот метод борьбы со страхом и смертью, который является одним из приемлемых для индивида в современном мире.

12. С. Кьеркегор отмечал, что «бесконечный же страх перед единственной опасностью делает все прочие несуществующими» [12, с. 28]. Можно согласиться с этим мнением лишь отчасти. Дело в том, что бесконечный страх вызывает в человеке чувство тварности, чувство самосохранения, стремление к жизни (если только интенсивность страха не вызывает состояние «ступора», из-за чрезмерной его энергетики). Д. Юм указывал на определённое противоречие: жизнь не довольствует, 
а смерть страшит, поэтому именно смерть заставляет продолжать существование [30]. Для игры свойственно ослабление взаимосвязи жизни и смерти, а также наблюдается снижение степени их категоричности.

13. Для мифологической традиции характерной чертой является ретроспектива к онтологическому генезису [20], как правило, с целью восстановления идеального времени. М. Элиаде отмечал, что существует разница между сознанием архаического и современного индивида: для последнего все произошедшие события необратимы, для первого - это не является очевидным [20]. В данном аспекте существует определённая параллель между мифом и видеоиграми. В игровом «мифе о вечном возвращении» присутствует некая специфическая экзистенциальная ностальгия - желание вернуться в лучшее время, где существует возможность совершить иное действие, принять иное решение, где всё известно, хотя по сути это является инвариантностью всё той же экзистенции, но тем не менее с более благоприятным содержанием.

14. Имея возможность контролировать то, что вызывает страх, исключается возможность его появления, ибо ограничивая и контролируя что-либо - исчезает неизвестность и рассеивается, то, что вызывает страх.

15. Выше было указанно о специфике времени и пространства, так называемого священного времени. Аномалия и необычность указывают на то, что феномен, предмет или нечто иное имеют место за пределами объективной человеческой реальности. М. Элиаде указывал, что для перехода в «иной мир», само состояние индивида должно соответствовать состоянию искомого мира [24]. Такова особенность трансгрессии, которая предполагает не только ментальную подготовку индивида, но и чёткий ритуализм, время и обстановку (как, например, в инициации). Или ярким примером является то, что многие религии ведут богослужения на «священном языке» (латынь, древнеславянский язык и т. д.), для того чтобы отделить время священное от профанного [22]. Иными словами аномалии и необычность - это не всегда черты негативного, но всегда нуминозного, часто воссоздаются в ритуалах и культах, дабы разграничить время. Пространство видеоигры построено аналогично.

16. В данном случае мог бы быть применим опыт идеалистических школ или опыт реалистов и рационалистов, т. е. концепций, где признаётся первичность идей (реалий). Однако в таком случае возникает множество вопросов: например, где эти идеи существуют, есть одна идея игры или каждой игры в отдельности, каким образом они проникают в объективную реальность и т. д.

17. Главный вопрос, который возникает в данной ситуации, если нет связи с объективным миром, то каким образом мы можем приобщиться к внутреннему содержанию игры (сюжетом, внутренними связями, персонажами и т. д.). Если отбросить идеалистические концепции в понимании автономности мира видеоигр то, подобно тому, как религиозно-мифологические концепции есть продукт человеческого мышления, творчества и т. д., такое же положение может быть характерно и для игры. Если же мир видеоигр не имеет сходства с объективной реальностью индивида, то тогда невозможна дивинация, т. е. узнавание. В таком случае мир видеоигр для индивида был бы чем-то аморфным, хаотичным и полностью непонятным. А такое положение абсурдно.

18. При исследовании необходимо также учитывать и когнитивные способности индивида, которые также определяются его экзистенцией. Несомненно, что в данной ситуации (при исследовании мира видеоигр) не стоит упускать антропный прин- 
цип. Хотя и исходить в суждениях только одного мышления индивида являет опасность солипсизма, сенсуализма, радикального эмпиризма и т. д.

19. Подобный опыт не исключает объективный мир и человека, который является его частью. Более того, автономность виртуального пространства исключает понятия времени и пространства, а их присутствие в играх неотъемлемо.

20. М. Элиаде указывал, что часто в различных мифологических системах, божестводемиург, уходя, передаёт свои функции иным божествам [20] или героям [24]. Эти герои создают новые вещи и феномены, которые являются частью общей космогонии, ведь миф о сотворении вещи является неотъемлемым элементом космогонических мифологем [31].

21. Унификация и формализация отсутствуют ввиду того, что каждый игрок имеет индивидуальный стиль игры, принимает различные решения, различную тактику и стратегию. Особенно это заметно в играх, где имеет место вариации (выбор из нескольких вариантов).

22. Абсурдной является концепция, при которой исключался бы человек как активный элемент игрового пространства. Такое возможно, если предположить, что мир видеоигры создаёт под себя игрока, а не наоборот. Но такое положение абсурдно: в таком случае игрок пассивен и может лишь претерпевать изменения. Однако по факту игрок сам принимает решения на основе тех задач, которые ставит перед ним виртуальный мир, и делает это исходя из самого себя (ментальность). Кроме того, сам игрок решает вопрос, когда ему присутствовать в мире видеоигр, а когда закончить это присутствие. Таким образом, невозможно утверждать категорическую «необходимость» и детерминированность игрока от мира игры.

23. Игра зачастую позволяет реализовать такой нравственный акт, как самопожертвование. Причина в том, что индивид осознаёт, что он ничего не теряет и после смерти снова воскреснет. Это также некий момент «бессмертия» игрока.

24. Благодаря излишнему эстетизму многие феномены и вещи являются «косными», «мертвыми» и «неживыми». Таким образом, страхи, в том числе смерти, становятся искусственными и как бы обессиленными. Ярким примером этого служит особый эстетический образ монстров в видеоигре: с одной стороны, они принимают некую материальную оформленность (конечность), а с другой - феномены страха и смерти в такой парадигме устраняются, т. к. эстетический момент устраняет их реальность.

25. Существует исследование, согласно которому психологические заболевания, изображённые в играх, часто связывают с насилием, страхом, безумием, безнадежностью и т. д., иногда с паранормальными и сверхъестественными явлениями. Они, как и их последствия (страх, насилие и т. д.), ассоциируются с таинственностью, непредсказуемостью или непонятной болезнью, лечение которой требует экспериментального метода (нестандартного подхода), но, как правило, лекарства от неё не существует или лечение не работает, и весь игровой сюжет представляет собой бесконечную борьбу с безумием, собственным разумом и самим собой. Однако такие представления есть не что иное, как репрезентация самых распространённых предрассудков и стереотипов [32].

26. 3. Фрейд отмечал, что во времена первобытных форм религии существовал принцип «не убий», отражающийся в форме религиозной веры в духов [33]. 


\section{СПИСОК ЛИТЕРАТУРЫ}

1. Отто Р. Священное. Об иррациональном в идее божественного и его соотношении с рациональным. - СПб.: Изд-во Санкт-Петербургского университета, 2008. - 272 с.

2. Ницше Ф. Падение кумиров: Избранное. - СПб.: Лениздат, 2014. - 224 с.

3. Бахтин М.М. Собрание сочинений в 6 томах. Том 1. - М.: Русские словари, 2003. - 958 с.

4. Паскаль Б. Мысли. - М.: Астрель, 2009. - 253 с.

5. Гоббс Т. Левиафан. - М.: Мысль, 2001. - 478 с.

6. Боден Л. Инки. Быт. Культура. Религия. - М.: Центрполиграф, 2004. - 255 с.

7. Фромм Э. Отделение от себя // Кризис сознания: сборник работ по «философии кризиса». - М.: Алгоритм, 2009. - С. 97-104.

8. Вебер М. Избранное. Образ общества. - М.: Юрист, 1994. - 704 с.

9. Леви-Брюль Л. Сверхъестественное в первобытном мышлении - М.: Академический проект, 2015. $428 \mathrm{c}$.

10. Бергсон A. Смех. URL: http://krotov.info/library/02_b/er/gson_smeh.htm (дата обращения 09.08.2019).

11. Кодекс Бусидо. Хагакурэ. Сокрытое в листве / Я. Цунэтомо и др. - М.: Эксмо, 2004. - 432 с.

12. Кьеркегор С. Болезнь к смерти. - М.: Академический проект, 2014. - 160 с.

13. Материалисты древней Греции / под ред. М.А. Дынника. - М.: Политическая литература, 1955. $238 \mathrm{c}$.

14. Geraci R.M., Recine N., Fox S. Grotesque gaming: the monstrous in online worlds // Preternature: Critical and Historical Studies on the Preternatural. - 2016. - V. 5. - № 2. - P. 213-236.

15. Хайдеггер М. Бытие и Время. - M.: Ad Marginem, 1997. - 452 с.

16. Гуревич А.Я. Избранные труды. Норвежское общество. - М.: Традиция, 2009. - 470 с.

17. Гуревич А.Я. История и сага. - М.: Наука, 1972. - 198 с.

18. Спеваковский А.Б. Самураи - военное сословие Японии. - М.: Наука, 1981. - 168 с.

19. Фромм Э. Синдром распада // Кризис сознания: сборник работ по «философии кризиса». - М.: Алгоритм, 2009. - С. 82-97.

20. Элиаде М. Аспекты мифа. - М.: Академический проект, 2010. - 251 с.

21. Спиноза Б. Этика. - М.: АСТ, 2001. - 336 с.

22. Бирлайн Дж.Ф. Параллельная мифология. - М.: КРОН-ПРЕСС, 1997. - 336 с.

23. Барт Р. Мифологии - М.: Академический проект, 2014. - 351 с.

24. Элиаде М. Тайные Общества. Обряды инициации и посвящения. - СПб.: Университетская книга, 1999. - 356 c.

25. Disruptive Games: Power and Control or Fantasy and Entertainment / E.E. Inglesis Barcellos, G. Botura, E. Inglesis Barcellos, M. Koji Nakata, L. Inglesis Barcellos // Advances in Human Factors in Wearable Technologies and Game Design: Proc. of the AHFE 2018 International Conferences on Human Factors and Wearable Technologies, and Human Factors in Game Design and Virtual Environments. - Orlando, Florida, USA, July 21-25, 2018. - Cham: Springer Science Publ., 2018. - P. 355-365.

26. Chittaro L., Sioni R. Existential video games: Proposal and evaluation of an interactive reflection about death // Entertainment Computing. - 2018. - V. 26. - P. 59-77.

27. Ролз Дж. Теория справедливости. - Новосибирск: Изд-во Новосибирского университета, 1995. 513 c.

28. Dumas R. The Monstrous-Feminine in Contemporary Japanese Popular Culture (East Asian Popular Culture). - Cham: Palgrave Macmillan Publ., 2018. - 217 p.

29. Аристотель. Метафизика. - М.: Издательство «Э», 2016. - 448 с.

30. Юм Д. Диалоги о Естественной Религии - М.: Профит Стайл, 2007. - 192 с.

31. Широкова Н.С. Мифы кельтских народов. - М.: Астрель, 2005. - 431 с.

32. Gaming with stigma: analysis of messages about mental illnesses in video games / M. Ferrari, S.V. Mcilwaine, G. Jordan, J.L. Shah, Sh. Lal, S.N. Iyer // JMIR Mental Health. - 2019. - V. 6. - № 5. URL: https://mental.jmir.org/2019/5/e12418/PDF (дата обращения 09.08.19)

33. Фрейд 3. Тотем и табу. - СПб.: Лениздат, 2014. - 224 с.

Поступила 12.08.2019 2. 
UDC 101.1:316+613.43:004.925.84

\title{
THE PHENOMENON OF FEAR AND DEATH IN VIDEO GAMES
}

\author{
Nikolay I. Petev, \\ cyanideemo@mail.ru \\ Vladimir State University, \\ 87, Gorky street, Vladimir, 600000, Russia.
}

Nikolay I. Petev, Cand. Sc., associate professor, Vladimir State Universityю

This article discusses the phenomena of fear and death in video games. It should be noted that in some video games there is a specific numinous character, which affects the internal content of the above phenomena. In general, the space and time of the virtual world of games, different from the subjective world, lead to the fact that fear and death are exhausted, they lose their energy, categorical, and the individual has a special state outside them. The relevance of this work consists in considering fear controlling, as well as those metamorphoses that occur with it, as well as with the individual in the space of video games. The aim of the research is to identify the specifics of construction and presentation of the phenomenon of fear and death within the space and plot of video games; to determine the features of the internal content of these phenomena, as well as their hermeneutic analysis to obtain those substantive ideas that reflect the essence of these phenomena; to consider such phenomena as time, space, implantation, etc. in synthetic interweaving, as a special form of artificially created existence of the individual. Methods. Abstract-logical, comparative and hermeneutic analyses are applied in this work to establish the main provisions of the studied question. In addition, the dialectical method is used for more detailed analysis of the phenomenon of fear and death and elements of religious analysis. Results. Video games, through the prism of the phenomena of fear and death, carry out a breakthrough of the individual's consciousness in a certain sphere of numinous (religious, sacred, or rather in a certain plane of "completely different» and different from the profane). This is necessary, first of all, to combat the commonplace, which leads to the alienation of the individual from himself. In other words, fear and death initiate an individual's existential sensitivity. Video games serve as a certain mechanism (method) to combat various phobias of individual, collective and archaic character, giving them a specific (physical, material, which can be destroyed) form. Video games are a form of expression of thanatological (eschatological, sometimes apocalyptic) tendencies as a compensatory component. In addition, it is worth pointing out that the space, gameplay and artificial reality of these games contribute to implementation of teleology, etiology, heroic ethics, «immortality» of the individual, as well as going beyond their own existence (in particular, in terms of the concepts of time and space), using fear and the phenomenon of death as an instrument.

Key words: Video games, fear, death, numinous, alienation from death, divinity, time, space.

\section{REFERENCES}

1. Otto R. Svyashchennoe. Ob irratsionalnom v idee bozhestvennogo i ego sootnoshenii s ratsionalnym [Sacred. On the irrational in the idea of the divine and its relation with the rational]. St. Petersburg, StPetersburg University Publ., 2008. 272 p.

2. Nitsshe F. Padenie kumirov: Izbrannoe [The fall of idols: favorites]. St. Petersburg, Lenizdat Publ., 2014. 224 p.

3. Bakhtin M.M. Sobranie sochineniy v 6 tomakh. T. 1 [Collected works in 6 volumes. Vol. 1]. Moscow, Russkie slovari Publ., 2003. 958 p.

4. Paskal B. Mysli [Thoughts]. Moscow, Astrel Publ., 2009. 253 p.

5. Gobbs T. Leviafan [Leviathan]. Moscow, Mysl Publ., 2001. 478 p.

6. Boden L. Inki. Byt. Kultura. Religiya [Incs. Life. Culture. Religion]. Moscow, Tsentrpoligraf Publ., 2004. $255 \mathrm{p}$. 
7. Fromm E. Otdelenie ot sebya [Separation from oneself]. Krizis soznaniya: sbornik rabot po «filosofii krizisa» [Crisis of consciousness: a collection of works on the «philosophy of the crisis»]. Moscow, Algoritm Publ., 2009. pp. 97-104.

8. Veber M. Izbrannoe. Obraz obshchestva [Favourites. Image of society]. Moscow, Yurist Publ., 1994. 704 p.

9. Levi-Bryul L. Sverkhestestvennoe v pervobytnom myshlenii [Supernatural in primitive thinking]. Moscow, Akademicheskiy proekt Publ., 2015. 428 p.

10. Bergson A. Smekh [Laughter]. Available at: http://krotov.info/library/02_b/er/gson_smeh.htm (accessed 9 August 2019).

11. Tsunemoto Ya. Kodeks Busido. Khagakure. Sokrytoe v listve [The Code of Bushido. Hagakure. Hidden in the foliage]. Moscow, Eksmo Publ., 2004. 432 p.

12. Kerkegor S. Bolezn $k$ smerti [The sickness unto death]. Moscow, Akademicheskiy proekt Publ., 2014. $160 \mathrm{p}$.

13. Materialisty drevney Gretsii [Materialists of ancient Greece]. Ed. by M.A. Dynnik. Moscow, Politicheskaya literatura Publ., 1955. 238 p.

14. Geraci R.M., Recine N., Fox S. Grotesque gaming: the monstrous in online worlds. Preternature: Critical and Historical Studies on the Preternatural, 2016, vol. 5, no. 2, pp. 213-236.

15. Khaydegger M. Bytie i Vremya [Being and time]. Moscow, Ad Marginem Publ., 1997. 452 p.

16. Gurevich A.Ya. Izbrannye trudy. Norvezhskoe obshchestvo [Selected works. Norwegian society]. Moscow, Traditsiya Publ., 2009. 470 p.

17. Gurevich A.Ya. Istoriya i saga [History and Saga]. Moscow, Nauka Publ., 1972. 198 p.

18. Spevakovskiy A.B. Samurai - voennoe soslovie Yaponii [Samurai - military class of Japan]. Moscow, Nauka Publ., 1981. 168 p.

19. Fromm E. Sindrom raspada [Syndrome of decay]. Krizis soznaniya: sbornik rabot po «filosofii krizisa» [Crisis of consciousness: a collection of works on the «philosophy of the crisis»]. Moscow, Algoritm Publ., 2009. pp. 82-97.

20. Eliade M. Aspekty mifa [Aspects of myth]. Moscow, Akademicheskiy proekt Publ., 2010. 251 p.

21. Spinoza B. Etika [Ethics]. Moscow, AST Publ., 2001. 336 p.

22. Birlain Dzh.F. Parallelnaya mifologiya [Parallel mythology]. Moscow, KRON-PRESS Publ., 1997. 336 p.

23. Bart R. Mifologii [Mythologies]. Moscow, Akademicheskiy proekt Publ., 2014. 351 p.

24. Eliade M. Taynye Obshchestva. Obryady initsiatsii i posvyashcheniya [Secret society. The rites of initiation and dedication]. St. Petersburg, Universitetskaya kniga Publ., 1999. 356 p.

25. Inglesis Barcellos E.E., Botura G., Inglesis Barcellos E., Koji Nakata M., Inglesis Barcellos L. Disruptive Games: Power and Control or Fantasy and Entertainment. Advances in Human Factors in Wearable Technologies and Game Design. Proc. of the AHFE 2018 International Conferences on Human Factors and Wearable Technologies, and Human Factors in Game Design and Virtual Environments. Orlando, Florida, USA, July 21-25, 2018. Cham, Springer Science Publ., 2018. pp 355-365.

26. Chittaro L., Sioni R. Existential video games: Proposal and evaluation of an interactive reflection about death. Entertainment Computing, 2018, vol. 26, pp. 59-77.

27. Rolz Dzh. Teoriya spravedlivosti [Theory of justice]. Novosibirsk, Novosibirsk University Publ., 1995. $513 \mathrm{p}$.

28. Dumas R. The Monstrous-Feminine in Contemporary Japanese Popular Culture (East Asian Popular Culture). Cham, Palgrave Macmillan Publ., 2018. 217 p.

29. Aristotel. Metafizika [Metaphysics]. Moscow, «E» Publ., 2016. 448 p.

30. Yum D. Dialogi o Estestvennoy Religii [Dialogues about natural religion]. Moscow, Profit Stayl Publ., 2007. 192 p.

31. Shirokova N.S. Mify keltskikh narodov [Myths of the Celtic peoples]. Moscow, Astrel Publ., 2005. 431 p.

32. Ferrari M., Mcilwaine S.V., Jordan G., Shah J.L., Lal Sh., Iyer S.N. Gaming with stigma: analysis of messages about mental illnesses in video games. JMIR Mental Health, 2019, vol. 6, no. 5. Available at: https://mental.jmir.org/2019/5/e12418/PDF (accessed 9 August 2019).

33. Freyd Z. Totem i tabu [Totem and taboo]. St. Petersburg, Lenizdat Publ., 2014. 224 p.

Received: 12 August 2019. 